\title{
Fault Classification, Distance Location and Faulty Section Identification in Teed Transmission Circuits using Artificial Neural Network
}

\author{
Anamika Yadav \\ Department of Electrical \\ Engineering \\ National Institute of Technology \\ Raipur, 492010, C.G., India
}

\author{
Prarthana Walayani \\ Department of Electrical \\ Engineering \\ Bhilai Institute of Technology \\ Raipur, 492001, C.G., India
}

\author{
A. S. Thoke \\ Department of Electrical \\ Engineering \\ National Institute of Technology \\ Raipur, 492010, C.G., India
}

\begin{abstract}
An accurate fault classification and distance location algorithm for Teed transmission Circuit based on application of artificial neural networks (ANN) is presented in this paper. The proposed algorithm uses the fundamental component of voltage and current signals of each section measured at one end of teed circuit to detect, classify and locate the faults. ANN has the ability to classify the nonlinear relationship between measured signals by identifying different patterns of the associated signals. The adaptive protection scheme based on application of ANN is tested for shunt faults, varying fault location, fault resistance and fault inception angle. An improved performance is experienced once the neural network is trained adequately, which gives accurate results when faced with different system parameters and conditions. The entire test results clearly show that the fault is detected, classified and located within one cycle; thus the proposed adaptive protection technique is well suited for teed transmission circuit fault classification, distance location and faulty section identification. Results of performance studies show that the proposed neural network-based module can improve the performance of conventional fault selection algorithms.
\end{abstract}

\section{Keywords}

Artificial Neural Network, Teed Transmission circuit, Fault detection, Shunt faults.

\section{INTRODUCTION}

Protection of multi-terminal lines is not as simple as that of two-terminal lines. They usually experience additional problems caused by the intermediate infeed from the third terminal, or an outfeed to the terminal, difference in line length to tee point and also due to different source impedances [1]. Most of the work reported deals with two terminal lines with less attention to teed feeders transmission line configurations. In [2] the high frequency traveling-wave information contained in the post fault voltage and current signals are used for protection of teed circuits. The main problems of the traveling wave method is that it requires high sampling rates and has a difficulty in distinguishing between traveling waves from the fault and the remote end of the line. The wavelet transform analysis $[3,4]$ is based on the highfrequency components of the fault generated signals on each terminal of the system. The limitation stated is that at low signal-noise ratio (SNR), the method becomes inefficient. In a directional comparison technique [5] the polarity of the fault generated transient current signals is detected at each end of teed circuit and is then sent over to the line remote ends through communication link. A digital differential relaying scheme [6] involves deriving differential signals that are functions of both voltages and currents measured at each end. The scheme is based on master and slave principles using a fibre optic link as a means of communication between ends. Fault Location algorithm for locating unbalanced faults based on negative-sequence quantities from all line terminals for two or three terminal lines is reported in [7]. Fault location schemes using synchronized phasor measurements for multiterminal transmission line have been developed in [8-10]. There has been a very limited attention to the use of artificial neural network for protection of teed transmission circuit [11]. Eyada et. al [11] use radial basis function neural network for fault distance location in teed circuits and also detects the fault but the network does not identify the phase in which the fault occurs.

ANN is powerful in pattern recognition, classification and generalization. ANN-based techniques show a great enhancement in the accuracy of fault classification and location in comparison with the conventional techniques. This is due to the features of ANN which do not exist in the conventional methods such as the capability of non-linear mapping, parallel processing, learning and generalisation. In this work, we present an extension to our work which addresses double circuit transmission lines fault detection and classification based neural network [13], to teed circuit transmission line. Based on the authors' comprehensive digital simulations of the teed-circuit transmission systems, particular emphasis is placed on data preprocessing for feature extraction used as inputs to the ANN. The pattern classifier, i.e. the protection technique, is tested for shunt faults (LG: single phase to ground, LLG: double phase to ground, LL: phase to phase, LLLG: three phase to ground fault) under different fault locations, fault resistances, and fault inception angles. A $220 \mathrm{kV}$ teed-circuit line configuration is simulated using MATLAB®-Simpower and Simulink software.

\section{TEED TRANSMISSION SYSTEM MODELLING}

The system studied is composed of $220 \mathrm{kv}$ teed transmission circuit with section lengths $200 \mathrm{~km}$ (section-1), $120 \mathrm{~km}$ (section-2) and $110 \mathrm{~km}$ (section-3), connected to sources at each end. The single line diagram of the teed transmission circuit is shown in Fig. 1. Short circuit capacity of the equivalent thevenin sources on each sides of the line is considered to be $1.25 \mathrm{GVA}$ and $\mathrm{X} / \mathrm{R}$ ratio is 10 . The transmission line is simulated with distributed parameter line model using MATALB ${ }^{\circledR}$ software as shown in Fig.2. Teed circuit transmission line parameters are shown in Table 1. 


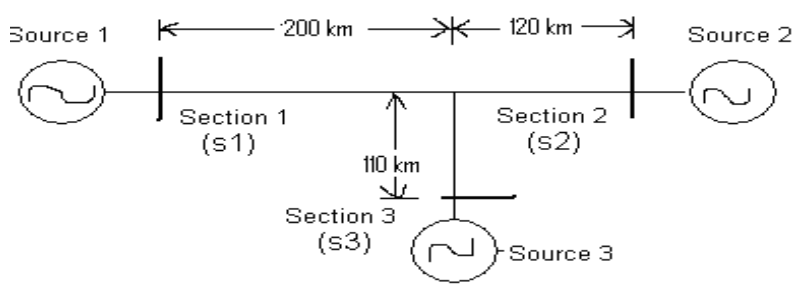

Fig.1 Single line diagram of power system under study.

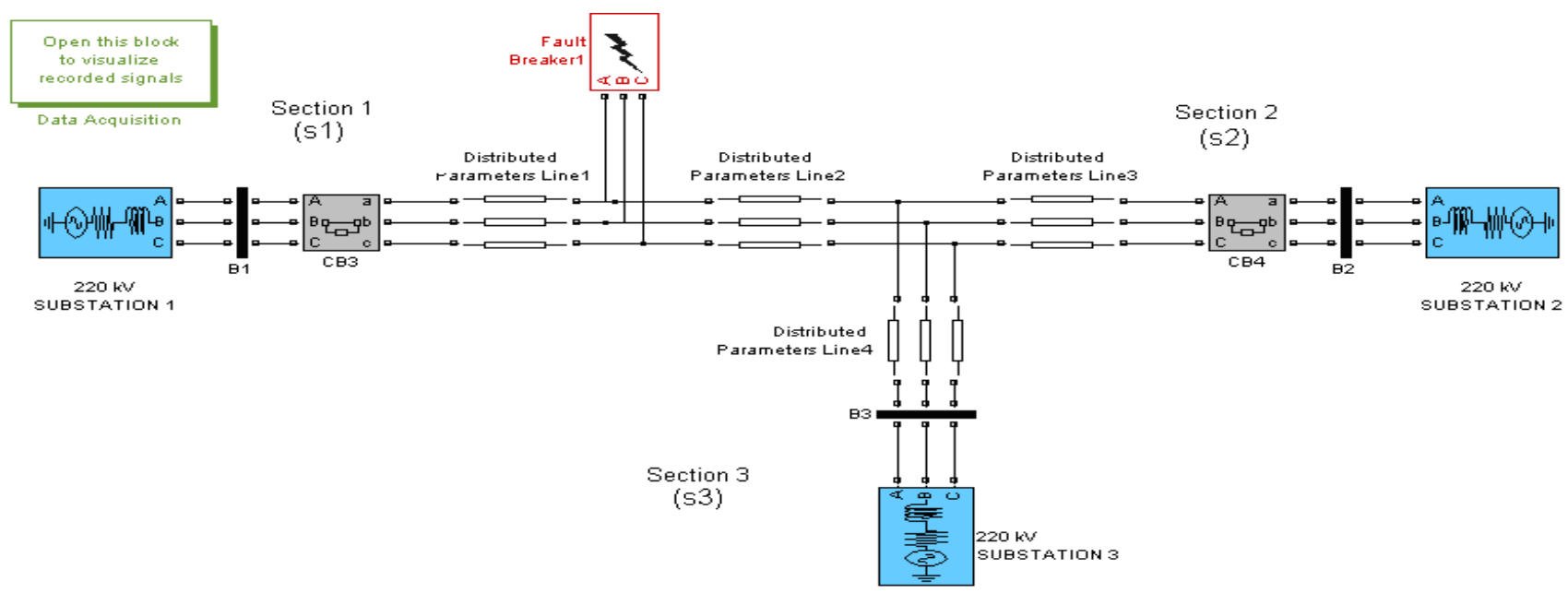

Fig.2. Power system model simulated in MATLAB Simulink software.

Preprocessing is a useful method that significantly reduces the size of the neural network and improves the performance and speed of training process [14]. Three phase voltages and three phase current input signals were sampled at a sampling frequency of $1 \mathrm{kHz}$ and further processed by simple 2 nd-order low-pass Butterworth filter with cut-off frequency of $400 \mathrm{~Hz}$. Subsequently, one full cycle Discrete Fourier transform is used to calculate the fundamental component of voltages and currents. The input signals were normalized in order to reach the ANN input level $( \pm 1)$.

Table 1 Teed circuit line parameter

\begin{tabular}{|l|l|}
\hline Positive sequence resistance $\mathrm{R} 1, \Omega / \mathrm{km}$ & 0.01809 \\
\hline Zero sequence resistance $\mathrm{R} 0, \Omega / \mathrm{km}$ & 0.2188 \\
\hline Positive sequence inductance $\mathrm{L} 1, \mathrm{H} / \mathrm{km}$ & 0.00092974 \\
\hline Zero sequence inductance $\mathrm{L} 0, \mathrm{H} / \mathrm{km}$ & 0.0032829 \\
\hline Positive sequence capacitance $\mathrm{C} 1, \mathrm{~F} / \mathrm{km}$ & $1.2571 \mathrm{e}-008$ \\
\hline Zero sequence capacitance $\mathrm{C} 0, \mathrm{~F} / \mathrm{km}$ & $7.8555 \mathrm{e}-009$ \\
\hline
\end{tabular}

\section{PROPOSED ANN BASED FAULT CLASSIFIER AND LOCATOR}

The various steps used to implement a neural network in the fault detection, classification and distance location algorithm in teed circuit transmission line is described below.

\subsection{Selecting the ANN architecture}

The network inputs chosen here are the magnitudes of the fundamental components $(50 \mathrm{~Hz})$ of three phase voltages and three phase currents of each section measured at one end. The basic task of fault classification is to determine the type of fault along with the phase; the outputs of the ANN are: three outputs corresponding to three phases, one output to represent whether neutral is involved in the fault loop and three outputs to represent in which line section fault is present. Thus, total seven outputs were considered to be provided by the network for fault classification. The inputs $\mathbf{X}_{1}$ and outputs $\mathbf{Y}_{1}$ for the fault classification network are:

$$
\begin{gathered}
X_{1}=\left[\begin{array}{l}
V_{a 1}, V_{b 1}, V_{c 1}, I_{a 1}, I_{b 1}, I_{c 1}, V_{a 2}, V_{b 2}, V_{c 2}, I_{a 2}, I_{b 2}, I_{c 2}, \\
V_{a 3}, V_{b 3}, V_{c 3}, I_{a 3}, I_{b 3}, I_{c 3}
\end{array}\right] \\
Y_{1}=[A, B, C, G, S 1, S 2, S 3]
\end{gathered}
$$

Similarly, for fault location task, where we have to determine the distance to the fault, it was decided that the distance to the fault in $\mathrm{km}$ with regard to the total length of the line should be the only output provided by the fault location network. Thus the input $\mathbf{X}_{2}$ and the output $\mathbf{Y}_{2}$ for the fault location network are:

$$
\begin{aligned}
X_{2} & =\left[\begin{array}{l}
V_{a 1}, V_{b 1}, V_{c 1}, I_{a 1}, I_{b 1}, I_{c 1}, V_{a 2}, V_{b 2}, V_{c 2}, I_{a 2}, I_{b 2}, I_{c 2}, \\
V_{a 3}, V_{b 3}, V_{c 3}, I_{a 3}, I_{b 3}, I_{c 3}
\end{array}\right] \\
Y_{2} & =\left\lfloor L_{f}\right\rfloor
\end{aligned}
$$

The number of neurons in hidden layer is determined empirically by experimenting with various network configurations. Through a series of trials and modifications of the ANN architecture, the best performance was achieved by using a three layer network with 18 neurons in the input layer, 13 neurons in the hidden layer, and 7 neurons in the output layer as shown in Fig. 3. The final determination of the neural network requires the relevant transfer functions in the hidden and output layers to be established. Activation function of the hidden layer is hyperbolic tangent sigmoid function. Neurons with sigmoid function produce real valued outputs that give the ANN ability to construct complicated decision boundaries in an n-dimensional feature space. This is important because the smoothness of the generalization function produced by the neurons, and hence its classification ability, is directly dependent on the nature of the decision boundaries. Saturating linear transfer function (Satlin) has been used in the output layer as shown in Fig. 3. Depending on the fault type which 
occurs on the system, various outputs of the network should be 0 or 1 . For fault distance location task, three layer network with 18 neurons in the input layer, 40 neurons in the hidden layer and 01 in the output layer was found to be suitable with pure linear function "purelin" in the output layer as shown in Fig. 4.

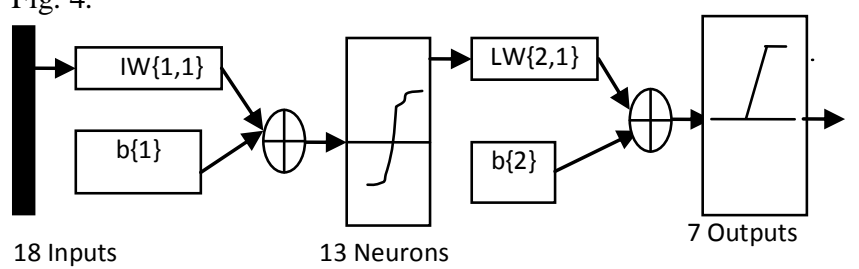

Fig.3. Structure of ANN Based Fault Detector and Classifier

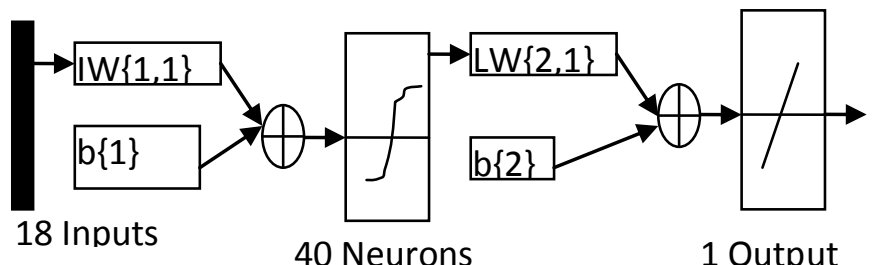

Fig.4. Structure of ANN Based Fault Locator

\subsection{Training Process}

Using SIMULINK \& SimPowerSystem toolbox of MATLAB each type of fault (SLG, LLG, LL, LLLG each section) at different fault locations between $0-90 \%$ of line length and fault inception angles between $0 \& 90^{\circ}$ have been simulated as shown below in Table 2. The number of fault simulated for single phase to ground faults (AG, BG, CG for each section) are: 180 for section $1(=3 * 10 * 3 * 2)$ i.e. (types of fault *number of fault locations*fault resistances*fault inception angles), $108(=3 * 6 * 3 * 2)$ for section 2 and $108(=3 * 6 * 3 * 2)$ for section 3 . Thus, the total number of fault cases simulated for single phase to ground faults is 396 . The number of cases simulated for double phase to ground faults $(\mathrm{ABG}, \mathrm{BCG}$ and CAG) for each section is: $360(3 * 20 * 3 * 2$ for section 1$), 216$ $(3 * 12 * 3 * 2$ for section 2$)$ and $198(3 * 11 * 3 * 2$ for section 3$)$ forming total number of fault cases simulated for double phase to ground faults as 774. The number of cases studied for phase to phase faults $(\mathrm{AB}, \mathrm{BC}, \mathrm{CA})$ for each section are: 120 $(3 * 20 * 1 * 2$ for section 1$), 72(3 * 12 * 1 * 2$ for section 2$)$ and 66 $(3 * 11 * 1 * 2$ for section 3$)$ forming total number of fault cases simulated for phase to phase faults are 258. Similarly, the number of cases simulated for three phase to ground faults are $120(1 * 20 * 3 * 2$ for section 1$), 72(1 * 12 * 3 * 2$ for section 2$)$ and $66(1 * 11 * 3 * 2$ for section 3$)$, which add to a total 258 cases. From each fault case ten numbers of post fault samples have been extracted to form the data set for neural network. 40 samples during no fault are also collected for the fault classification task. Thus, the total number of patterns generated for training is 16900 for the fault classification and location task. When network was trained with large training data set, it requires large memory and large computing time. Therefore, speed of training is very low. In order to compensate for this four different modules i.e. single phase to ground, double phase to ground, phase to phase and three phase to ground fault classifiers and four corresponding locator modules are designed for fault classification and location task.
Table 2 Patterns Generation

\begin{tabular}{|l|l|l|}
\hline S.No. & Parameters & \multicolumn{1}{c|}{ Set values } \\
\hline 1. & Fault type & $\begin{array}{l}\text { AG,BG,CG,ABG,BCG, } \\
\text { CAG,AB,BC,CA,ABCG }\end{array}$ \\
\hline 2. & $\begin{array}{l}\text { Fault location in } \\
\text { km }\end{array}$ & $\begin{array}{l}\text { Section } 1-0,10,20,30 \ldots .190 \mathrm{~km} \\
\text { Section 2 - 0,10,20,30...110 km } \\
\text { Section 3 - } 0,10,20,30 \ldots .100 \mathrm{~km}\end{array}$ \\
\hline 3. & $\begin{array}{l}\text { Fault inception } \\
\text { angle }\end{array}$ & $0^{\circ}$ and $90^{\circ}$ \\
\hline 4. & Fault resistance & 0,50 and $100 \Omega$ \\
\hline
\end{tabular}

The networks for fault classification and fault distance location were trained using Levenberg-Marquardt training algorithm using neural network toolbox of Matlab [15]. Architectures of ANN based fault classifier and locator modules are shown in Table 3. The number is epochs required for training varies from 50 to 350 to reduce the mean square error below 0.001. As the training is done off line, the iterations and time required for training are not of great concern. The trained network is tested for new cases, not covered in training pattern to demonstrate the viability of the proposed network.

Table 3 Architectures of ANN Based Fault Classifiers and Locators

\begin{tabular}{|c|c|c|c|c|c|c|}
\hline \multirow{2}{*}{$\begin{array}{l}\text { S. } \\
\text { No }\end{array}$} & \multirow{2}{*}{$\begin{array}{l}\text { Type of } \\
\text { network }\end{array}$} & \multicolumn{3}{|c|}{ Number of neurons } & \multirow{2}{*}{$\begin{array}{l}\text { Mean } \\
\text { square } \\
\text { error }\end{array}$} & \multirow{2}{*}{$\begin{array}{l}\text { No. } \\
\text { of } \\
\text { epoch }\end{array}$} \\
\hline & & $\begin{array}{l}\text { Input } \\
\text { layer }\end{array}$ & $\begin{array}{l}\text { Hidden } \\
\text { layer }\end{array}$ & $\begin{array}{l}\text { Output } \\
\text { layer }\end{array}$ & & \\
\hline 1. & $\begin{array}{l}\text { LG } \\
\text { classifier }\end{array}$ & 18 & 13 & 7 & $\begin{array}{l}1.79019 \\
\mathrm{e}-04\end{array}$ & 66 \\
\hline 2. & $\begin{array}{l}\text { LLG } \\
\text { classifier }\end{array}$ & 18 & 13 & 7 & $\begin{array}{l}1.09385 \\
\mathrm{e}-027\end{array}$ & 64 \\
\hline 3. & $\begin{array}{l}\text { LL } \\
\text { classifier }\end{array}$ & 18 & 13 & 7 & $\begin{array}{l}2.74725 \\
\mathrm{e}-04\end{array}$ & 37 \\
\hline 4. & $\begin{array}{l}\text { LLLG } \\
\text { classifier }\end{array}$ & 18 & 13 & 7 & $\begin{array}{l}2.1978 \\
\text { e- }-004\end{array}$ & 58 \\
\hline 5. & $\begin{array}{l}\text { LG } \\
\text { locator }\end{array}$ & 18 & 40 & 1 & $\begin{array}{l}1.16026 \\
e-003\end{array}$ & 300 \\
\hline 6 & $\begin{array}{l}\text { LLG } \\
\text { locator }\end{array}$ & 18 & 40 & 1 & $\begin{array}{l}8.79447 \\
\text { e- } 005\end{array}$ & 300 \\
\hline 7. & $\begin{array}{l}\mathrm{LL} \\
\text { locator }\end{array}$ & 18 & 40 & 1 & $\begin{array}{l}7.68118 \\
\text { e- } 007\end{array}$ & 350 \\
\hline 8. & $\begin{array}{l}\text { LLLG } \\
\text { locator }\end{array}$ & 18 & 40 & 1 & $\begin{array}{l}6.55253 \\
e-006\end{array}$ & 300 \\
\hline
\end{tabular}

4. TEST RESULTS OF ANN BASED FAULT DETECTOR, CLASSIFIER AND LOCATOR

ANN based Fault detector, classifier and locator modules were then extensively tested using independent data sets consisting of fault scenarios never used previously in training. Fault type, fault location and fault inception angle were changed to investigate the effects of these factors on the performance of the proposed algorithm.

\subsection{Test results of single phase to ground fault (LG)}

The network was tested by presenting different single phase to ground fault cases with varying fault locations $(0-90 \%$ of total length) and fault inception angles $\left(\Phi_{i}=0-360^{\circ}\right)$. Fig.5 (a,b) and Fig.6 show the test results of the ANN based fault classifier and fault locator module respectively for " $\mathrm{B}$ " phase to ground fault in section-1 at $70 \mathrm{~km}$, for fault inception time $72.5 \mathrm{~ms}\left(\Phi_{\mathrm{i}}=225^{\circ}\right)$ and fault resistance $R_{f}=75 \Omega$. It is clear from Fig.5 (a,b) that all the outputs of ANN are low (0) before the inception of fault and further after the inception of fault at 
$72.5 \mathrm{~ms}$ the output of the corresponding phase "B", ground "G" and the faulty section "S1" becomes high (1) at $91 \mathrm{~ms}$ time i.e. within one cycle time and all other outputs are low. Thus, the fault is simultaneously detected and classified and also the section is identified.

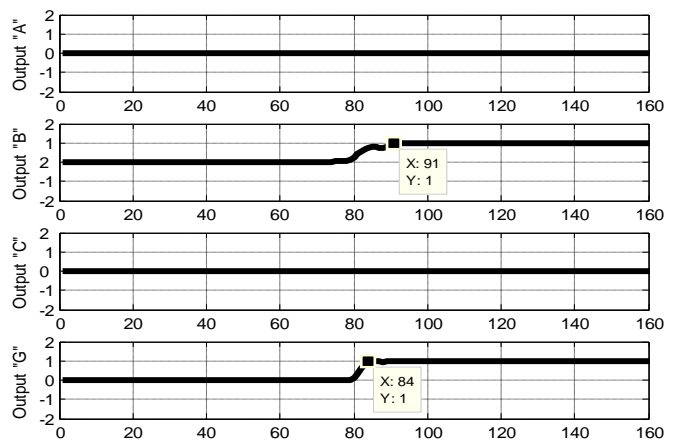

Fig.5(a)

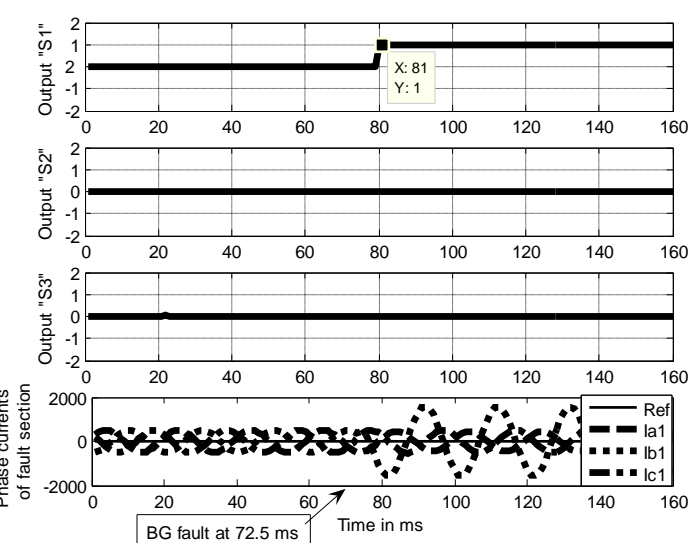

Fig.5(b)

Fig.5.(a, b) Test result of single phase to ground fault classifier module for BG fault at $70 \mathrm{~km}$ from section-1 at

fault inception time $=72.5 \mathrm{~ms}\left(\Phi_{\mathrm{i}}=225^{\circ}\right)$ and fault resistance $R_{\mathrm{f}}=75 \Omega$.

The output of ANN based fault locator i.e. estimated fault location $\left(\mathrm{L}_{\mathrm{e}} \mathrm{km}\right)$ as shown in Fig. 6 is 69.441 at $89 \mathrm{~ms}$ as against the actual fault location $70 \mathrm{~km}$, after one cycle from the inception of fault; thus the percentage error in estimation of fault location is $0.294 \%$.

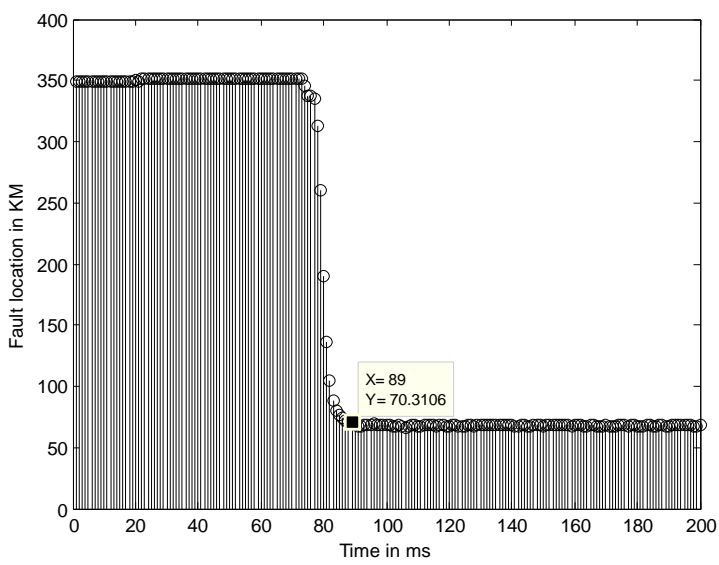

Fig.6. Test result of single phase to ground fault locator module for BG phase to ground fault at $70 \mathrm{~km}$ from section-1 at fault inception time $=72.5 \mathrm{~ms}\left(\Phi_{\mathrm{i}}=225^{\circ}\right)$ and fault resistance $R_{\mathrm{f}}=75 \Omega$.

\subsection{Test results of double phase to ground fault (LLG)}

The network is tested for a double phase to ground fault "ABG" fault in section-2 at $52 \mathrm{~km}$, fault inception time is $60 \mathrm{~ms}\left(\Phi_{\mathrm{i}}=0^{\circ}\right)$ and fault resistance $\mathrm{R}_{\mathrm{f}}=60 \Omega$. Fig. $7(\mathrm{a}, \mathrm{b})$ and Fig. 8 shows the test results of the ANN based fault detector, classifier and fault locator module. The output of ANN becomes high after $71 \mathrm{~ms}$ time in corresponding phases A, B, ground " $G$ " and section-2 and all other outputs are low. Also the estimated fault location is $51.9242 \mathrm{~km}$ at $81 \mathrm{~ms}$ as against the actual fault location $52 \mathrm{~km}$ as shown in Fig. 8, thus it is located accurately with $0.0689 \%$ error.
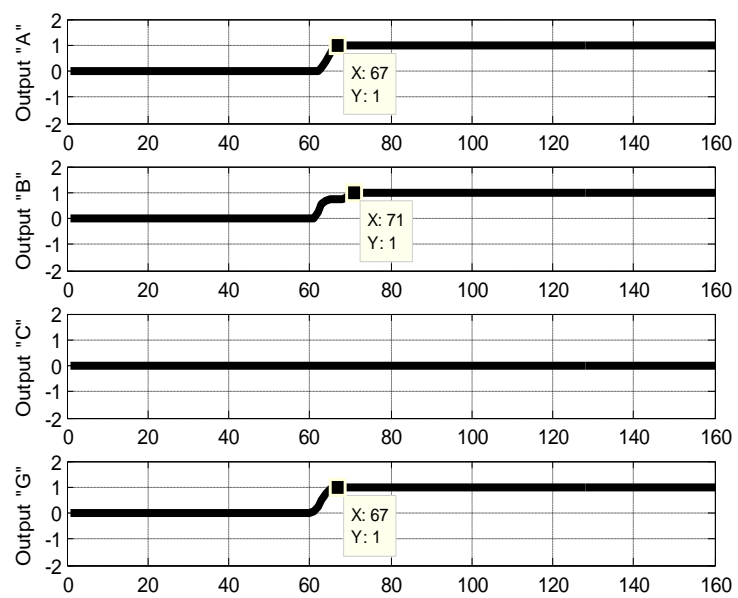

Fig.7(a)
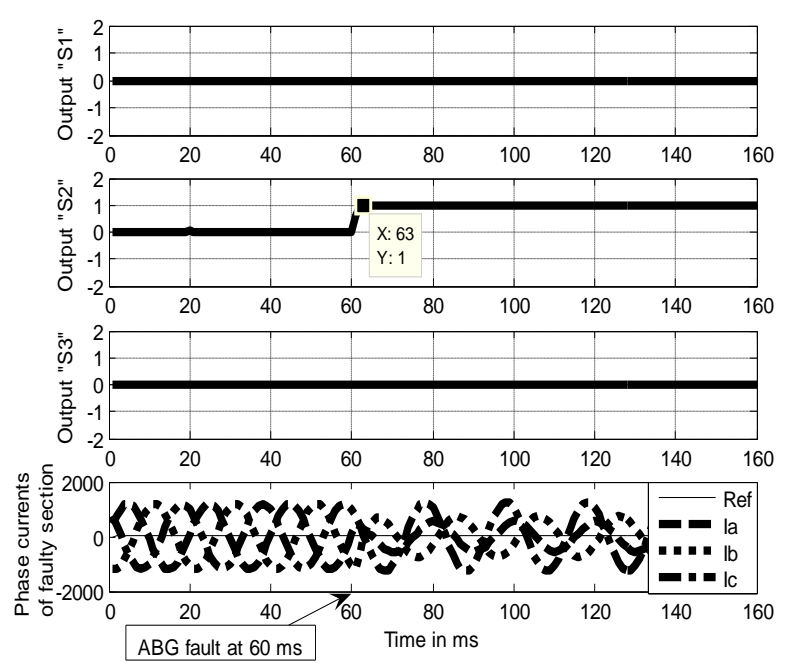

Fig.7(b)

Fig.7 (a,b). Test result of double phase to ground fault classifier module for ABG fault at $52 \mathrm{~km}$ from section-2 at fault inception angle $\Phi_{\mathrm{i}}=0^{\circ}(60 \mathrm{~ms})$, and fault resistance $\mathbf{R}_{\mathrm{f}}=\mathbf{6 0 \Omega}$. 


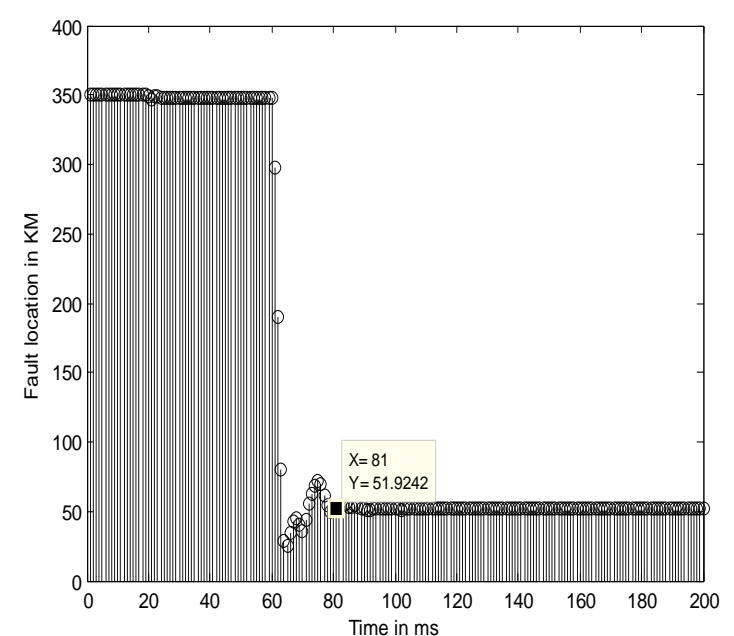

Fig.8. Test result of double phase to ground fault locator module for ABG fault at $52 \mathrm{~km}$ from section-2 at fault inception time $=60 \mathrm{~ms}\left(\Phi_{\mathrm{i}}=0^{\circ}\right)$, and fault resistance

$$
R_{\mathrm{f}}=60 \Omega \text {. }
$$

\subsection{Test results of phase to phase fault $L L$ )}

The test results of the ANN based fault detector, classifier and fault locator module for "CA" fault in section-2 at $45 \mathrm{~km}$, fault inception time $=70 \mathrm{~ms}\left(\Phi_{\mathrm{i}}=180^{\circ}\right)$ and fault resistance $\mathrm{R}_{\mathrm{f}}=$ $0 \Omega$ are shown in Fig. 9(a,b) and Fig. 10. The output of ANN becomes high (1) at $88 \mathrm{~ms}$ in corresponding phases "C and A" and section-2 within one cycle time from the inception of fault and all other outputs are low. The estimated fault location is $45.1375 \mathrm{~km}$ at $90 \mathrm{~ms}$ as against the actual fault location $45 \mathrm{~km}$ as shown in Fig. 10, thus the fault located is estimated accurately with $-0.125 \%$ error.

\subsection{Test results of three phase to ground \\ fault (LLLG)}

Fig. $11(\mathrm{a}, \mathrm{b})$ and Fig. 12 show the test results of the ANN based fault classifier and fault locator module for "ABCG" fault in section-1 at $75 \mathrm{~km}$ for fault inception time of $70 \mathrm{~ms}\left(\Phi_{\mathrm{i}}\right.$ $=180^{\circ}$ ) and fault resistance $R_{f}=75 \Omega$. The output of ANN shown in Fig. 11(a,b) becomes high (1) at $87 \mathrm{~ms}$ in corresponding phases "A, B, C, G" ground and section-2 within one cycle time from the inception of fault and all other outputs are low. The estimated fault location is $75.1028 \mathrm{~km}$ at $91 \mathrm{~ms}$ as against the actual fault location $75 \mathrm{~km}$ as shown in Fig. 12, thus the fault located is estimated accurately with $0.054 \%$ error.

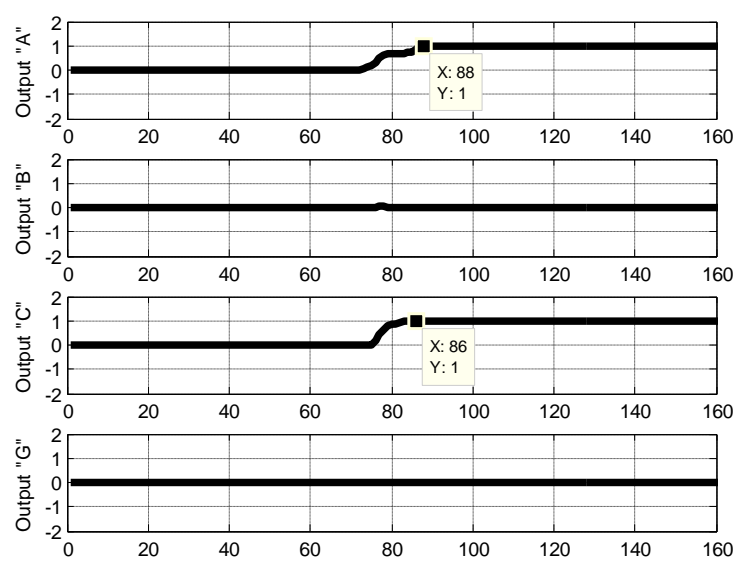

Fig.9(a)
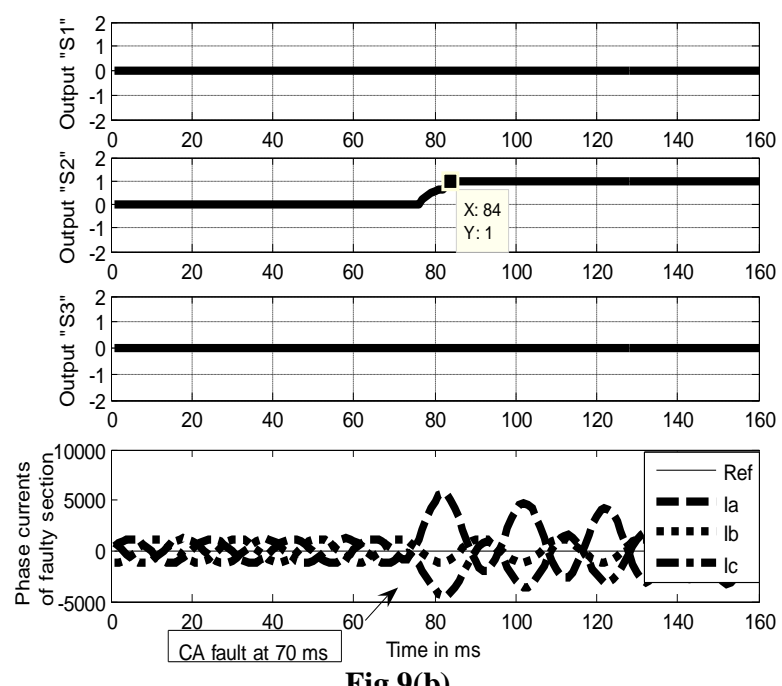
Fig.9(b)

Fig.9 (a,b). Test result of phase to phase fault classifier module for CA fault at $45 \mathrm{~km}$ from section-2 at fault inception time $=70 \mathrm{~ms}\left(\Phi_{\mathrm{i}}=180^{\circ}\right)$.

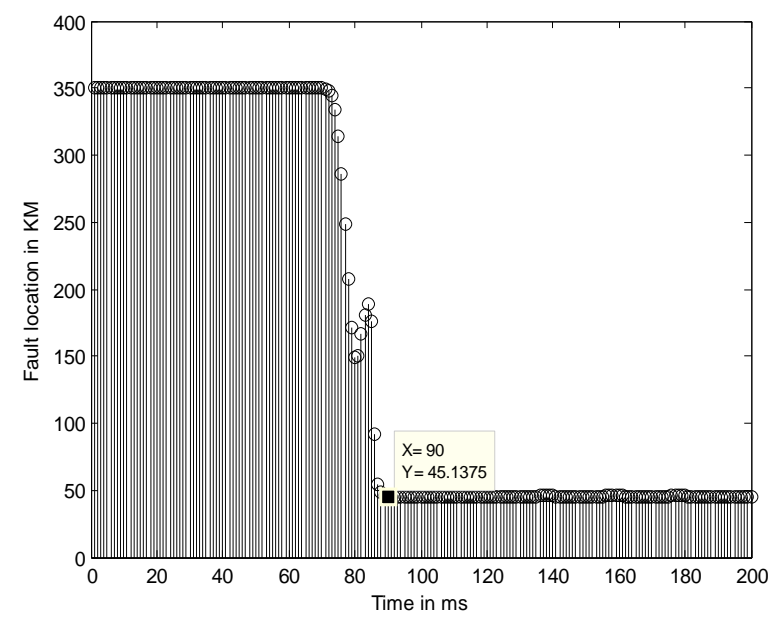

Fig.10. Test result of phase to phase fault locator module for CA fault at $45 \mathrm{~km}$ from section-2 at fault inception time $=70 \mathrm{~ms}\left(\Phi_{\mathrm{i}}=180^{\circ}\right)$. 


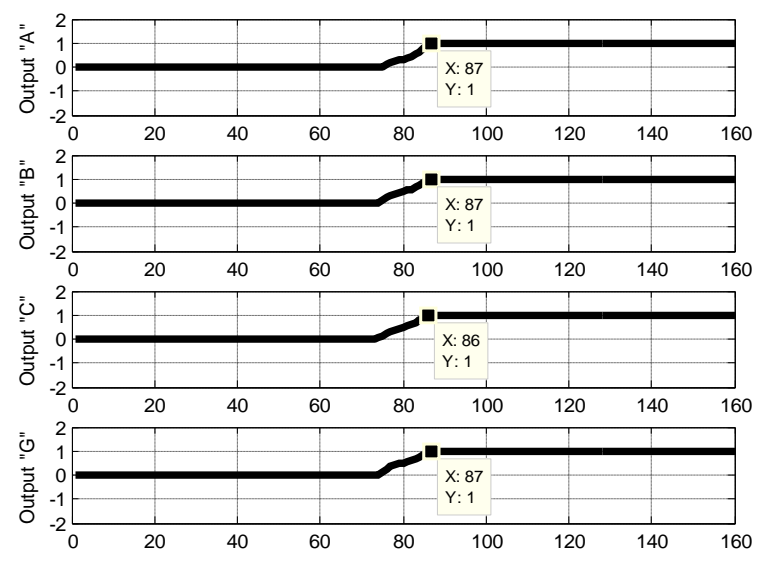

Fig.11(a)
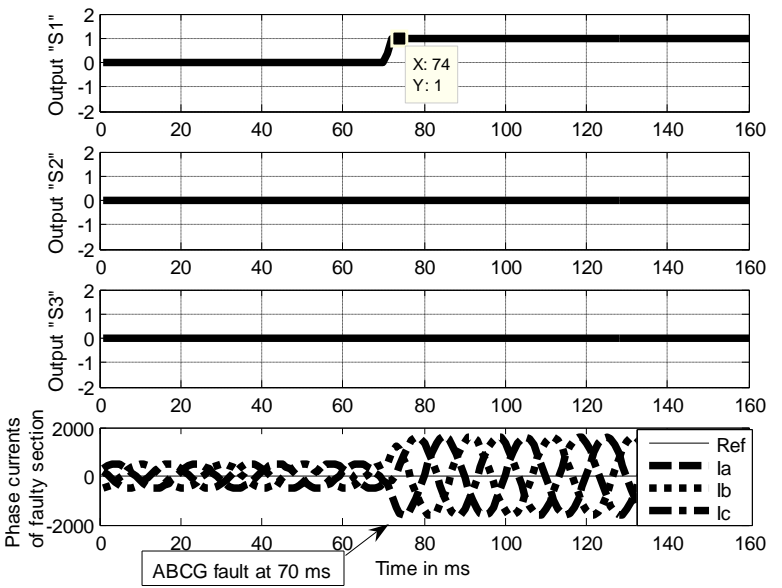

Fig.11(b)

Fig.11 (a,b). Test result of three phase to ground fault classifier module for ABCG fault at $75 \mathrm{~km}$ from section-1 at fault inception angle $\Phi_{i}=180^{\circ}$ and fault resistance $R_{\mathrm{f}}=75 \Omega$.

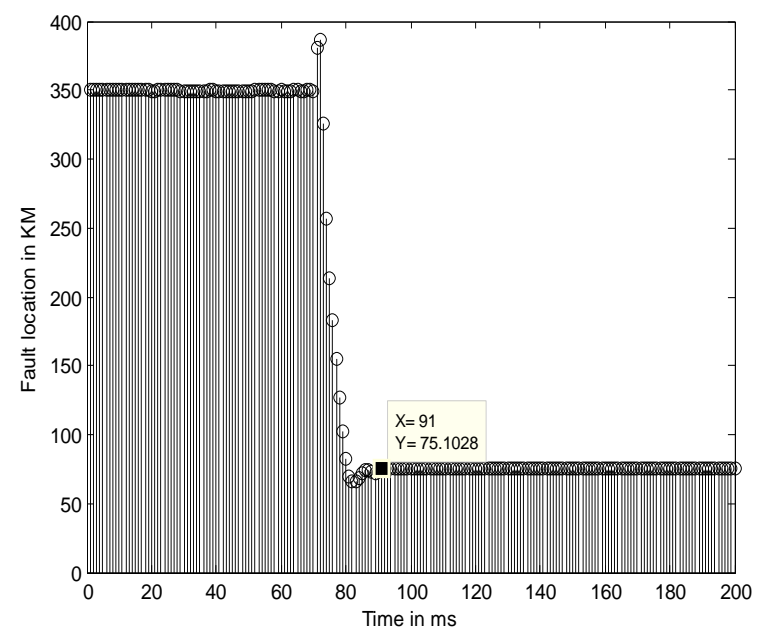

Fig.12. Test result of three phase to ground fault locator module for ABCG fault at $75 \mathrm{~km}$ from section-1 at fault inception angle $\Phi_{i}=180^{\circ}(70 \mathrm{~ms})$ and fault resistance $R_{\mathrm{f}}=75 \Omega$.

It is clear from test results shown above that, the faults are correctly detected, classified and faulty section is identified and located accurately. Some test results of ANN based fault detector, classifier and locator modules are shown in Table 4 and 5. During training of the neural network, samples of fault cases with only two values of fault inception angle $\left(0^{\circ}\right.$ and $\left.90^{\circ}\right)$ and three values of the fault resistance $(0,50$ and $100 \Omega)$ have been taken. However, while testing the neural network wide variation in fault inception angle $\left(0-360^{\circ}\right)$ and fault resistance $(0-100 \Omega)$ have been studied as shown in Table 4 and 5 .

Table 4. Test results of ANN based fault detector and classifier

\begin{tabular}{|c|c|c|c|c|c|c|c|c|c|c|c|}
\hline \multirow[t]{2}{*}{ Section } & \multirow[t]{2}{*}{$\begin{array}{l}\text { Fault } \\
\text { type }\end{array}$} & \multirow{2}{*}{$\begin{array}{c}\text { Fault } \\
\text { inception } \\
\text { angle in }\end{array}$} & \multirow[t]{2}{*}{$\begin{array}{l}\text { Fault location in } \\
\mathrm{km}\end{array}$} & \multirow[t]{2}{*}{$\begin{array}{c}\text { Fault resistance in } \\
\Omega\end{array}$} & \multicolumn{7}{|c|}{$\begin{array}{c}\text { ANN based fault detector and classifier } \\
\text { output }\end{array}$} \\
\hline & & & & & A & B & $\mathrm{C}$ & G & S1 & S2 & S3 \\
\hline \multirow[t]{10}{*}{1} & $\mathrm{AG}$ & 0 & 130 & 75 & 1 & 0 & 0 & 1 & 1 & 0 & 0 \\
\hline & BG & 225 & 70 & 75 & 0 & 1 & 0 & 1 & 1 & 0 & 0 \\
\hline & $\mathrm{CG}$ & 270 & 90 & 95 & 0 & 0 & 1 & 1 & 1 & 0 & 0 \\
\hline & $\mathrm{ABG}$ & 90 & 30 & 90 & 1 & 0 & 0 & 1 & 1 & 0 & 0 \\
\hline & BCG & 225 & 70 & 45 & 0 & 1 & 0 & 1 & 1 & 0 & 0 \\
\hline & CAG & 270 & 90 & 90 & 0 & 0 & 1 & 1 & 1 & 0 & 0 \\
\hline & $\mathrm{AB}$ & 90 & 30 & 0 & 1 & 0 & 0 & 1 & 1 & 0 & 0 \\
\hline & $\mathrm{BC}$ & 225 & 70 & 0 & 0 & 1 & 0 & 1 & 1 & 0 & 0 \\
\hline & $\mathrm{CA}$ & 315 & 110 & 0 & 0 & 0 & 1 & 1 & 1 & 0 & 0 \\
\hline & ABCG & 0 & 130 & 75 & 1 & 1 & 1 & 1 & 1 & 0 & 0 \\
\hline \multirow[t]{8}{*}{2} & $\mathrm{AG}$ & 45 & 90 & 95 & 1 & 0 & 0 & 1 & 0 & 1 & 0 \\
\hline & $\mathrm{CG}$ & 315 & 10 & 75 & 0 & 0 & 1 & 1 & 0 & 1 & 0 \\
\hline & $\mathrm{ABG}$ & 135 & 40 & 75 & 1 & 0 & 0 & 1 & 0 & 1 & 0 \\
\hline & BCG & 135 & 50 & 75 & 0 & 1 & 0 & 1 & 0 & 1 & 0 \\
\hline & CAG & 360 & 70 & 90 & 0 & 0 & 1 & 1 & 0 & 1 & 0 \\
\hline & $\mathrm{AB}$ & 45 & 90 & 0 & 1 & 0 & 0 & 1 & 0 & 1 & 0 \\
\hline & $\mathrm{CA}$ & 360 & 70 & 0 & 0 & 0 & 1 & 1 & 0 & 1 & 0 \\
\hline & ABCG & 270 & 10 & 75 & 0 & 1 & 0 & 1 & 0 & 1 & 0 \\
\hline \multirow[t]{4}{*}{3} & BG & 135 & 10 & 75 & 0 & 1 & 0 & 1 & 0 & 0 & 1 \\
\hline & $\mathrm{CG}$ & 360 & 70 & 95 & 0 & 0 & 1 & 1 & 0 & 0 & 1 \\
\hline & $\mathrm{ABG}$ & 45 & 30 & 75 & 1 & 0 & 0 & 1 & 0 & 0 & 1 \\
\hline & BCG & 135 & 10 & 50 & 0 & 1 & 0 & 1 & 0 & 0 & 1 \\
\hline
\end{tabular}




\begin{tabular}{|c|c|c|c|c|c|c|c|c|c|c|}
\hline CAG & 270 & 50 & 100 & 0 & 0 & 1 & 1 & 0 & 0 & 1 \\
\hline $\mathrm{BC}$ & 90 & 90 & 0 & 0 & 1 & 0 & 1 & 0 & 0 & 1 \\
\hline CA & 270 & 50 & 0 & 0 & 0 & 1 & 1 & 0 & 0 & 1 \\
\hline
\end{tabular}

Table 5 Test results of ANN based fault locator

\begin{tabular}{|c|c|c|c|c|c|c|}
\hline Section & $\begin{array}{l}\text { Fault } \\
\text { type }\end{array}$ & $\begin{array}{l}\text { Fault inception } \\
\text { angle in }{ }^{\circ}\end{array}$ & $\begin{array}{c}\text { Fault } \\
\text { resistance } \\
\text { in } \Omega\end{array}$ & $\begin{array}{l}\text { Fault location } \\
\text { in } \mathrm{km}\end{array}$ & $\begin{array}{l}\text { Calculated Output } \\
\text { Lf }(\mathrm{km})\end{array}$ & $\begin{array}{c}\text { Percentage } \\
\text { Error }(\%)\end{array}$ \\
\hline \multirow[t]{9}{*}{1} & $\mathrm{AG}$ & 135 & 50 & 78 & 77.57 & -0.215 \\
\hline & $\mathrm{BG}$ & 315 & 45 & 155 & 154.26 & -0.37 \\
\hline & $\mathrm{CG}$ & 90 & 75 & 168 & 168.76 & 0.38 \\
\hline & $\mathrm{ABG}$ & 90 & 60 & 30 & 30.584 & 0.292 \\
\hline & BCG & 180 & 45 & 50 & 49.23 & -0.385 \\
\hline & CAG & 270 & 100 & 90 & 90.595 & 0.2975 \\
\hline & $\mathrm{AB}$ & 225 & 0 & 70 & 69.33 & -0.335 \\
\hline & $\mathrm{BC}$ & 270 & 0 & 90 & 90.895 & 0.4475 \\
\hline & ABCG & 180 & 100 & 170 & 170.43 & 0.215 \\
\hline \multirow[t]{7}{*}{2} & $\mathrm{AG}$ & 180 & 50 & 89 & 89.54 & 0.45 \\
\hline & $\mathrm{CG}$ & 135 & 100 & 46 & 46.48 & 0.4 \\
\hline & $\mathrm{ABG}$ & 135 & 50 & 55 & 54.926 & -0.0617 \\
\hline & BCG & 180 & 75 & 40 & 40.377 & 0.314 \\
\hline & CAG & 315 & 50 & 85 & 84.16 & -0.70 \\
\hline & $\mathrm{AB}$ & 270 & 0 & 95 & 94.37 & -0.525 \\
\hline & $\mathrm{CA}$ & 90 & 0 & 57 & 57.32 & 0.266 \\
\hline \multirow[t]{6}{*}{3} & $\mathrm{AG}$ & 180 & 75 & 48 & 48.43 & 0.390 \\
\hline & $\mathrm{ABG}$ & 45 & 60 & 100 & 102.12 & 1.92 \\
\hline & BCG & 135 & 50 & 35 & 34.366 & -0.576 \\
\hline & CAG & 360 & 100 & 65 & 65.551 & 0.500 \\
\hline & $\mathrm{CA}$ & 135 & 0 & 86 & 86.45 & 0.409 \\
\hline & ABCG & 90 & 100 & 29 & 29.52 & 0.473 \\
\hline
\end{tabular}

In Tables 5, the maximum deviation of the estimated distance $\mathrm{L}_{\mathrm{e}}$ measured from the relay location and the actual fault location $\mathrm{L}_{\mathrm{f}}$ is calculated and the resulting estimated error " $\mathrm{e}$ " is expressed as a percentage of total line length $\mathrm{L}$ of that section as:

$$
e=\frac{L_{f}-L_{e}}{L} \times 100 \%
$$

In all the fault cases, the results show that the errors in locating the fault are in the range of $-0.7 \%$ to $+1.92 \%$. Thus, all test results are correct with reasonable accuracy.

\section{CONCLUSION}

An accurate algorithm and ANN architecture for fault detection, classification and distance location for shunt faults on teed circuit transmission line fed from sources at all three ends is presented in this work. The algorithm employs the fundamental components of three phase voltages and the three phase currents of each section measured at one end, thus requiring less communication. The algorithm provides automatic determination of fault type, faulted phases and fault distance location after one cycle from the inception of fault. The algorithm effectively eliminates the effect of varying fault location, fault inception angle and fault resistance. The performance of the proposed scheme has been investigated by a number of offline tests. The complexity of the possible types of faults (LG, LLG, LL, and LLLG for each section), varied fault locations $(0-90 \%)$, fault inception angles $\left(0 \& 360^{\circ}\right)$ and fault resistance $(0-100 \Omega)$ are investigated. The proposed scheme allows the protection engineers to increase the reach setting i.e. a greater portion of line length can be protected as compared to earlier techniques.

\section{REFERENCES}

[1] R. K. Aggarwal, D. V. Coury, A. T. Johns, and A. Kalam, "A practical approach to accurate fault location on extra high voltage teed feeders". IEEE - Trans.on Power Delivery, Vol. 8, Jul. 1993, pp. 874-883.

[2] P.G. McLarenm and S. Rajendra, "Travelling wave technique applied to the protection of teed circuits:principle of traveling - wave technique" IEEE Trans. on power apparatus and systems, Vol. PAS-104, No12, December 1985, pp. 3544 - 3550.

[3] L. L. Lai, E. Vaseekar, H. Subasinghe, N. Rajkumar, A. Carter, and B. J. Gwyn, "Application of wavelet transform and neural networks to fault location of a teed-circuit", IEE Seminar on Time-scale and TimeFrequency Analysis and Applications, London, Feb. 2000, pp. 15/1 - 15/5.

[4] M. da Silva, M. Oleskovicz, and D. V. Coury, "A Fault Locator for Three-Terminal Lines Based on Wavelet Transform Applied to Synchronized Current and Voltages Signals", IEEE PES Transmission and Distr. Conf. and Exposition, Latin America, Venezuela, 2006, pp. 1-6.

[5] Mao, P.L.; Bo, Z.Q.; Yao, L.Z.; Li, R.M., "Protection of teed transmission circuits using A new directional comparison technique", Proceedings of International Conference on Power System Technology (POWERCON), 18-21 Aug 1998, Vol.2, pp. 1111 1115.

[6] R.K. Aggarwal, A. T. Johns, "Digital differential relaying scheme for teed circuits based on voltage and 
current signal comparison", IEEE proceedings, Vol. 137 Pt.C, No.6, November 1990, pp. 414-423.

[7] D. A. Tziouvaras, J. B. Robrts, and G. Benmouyal, "New Multi-ended Fault Location Design for two- or three terminal lines", Proceedings of IEE Development in Power System Protection Conference, 2002, pp.395-398.

[8] S.M. Brahma and A.A. Girgis, "Fault location on a transmission line using synchronized voltage measurements", IEEE Transactions on Power Delivery, Vol. 19, No. 4, Oct. 2004, pp. 1619 - 1622.

[9] S.M. Brahma, "Fault location scheme for a multiterminal transmission line using synchronized voltage measurements", IEEE Transactions on Power Delivery, Vol. 20, No. 2, April 2005, pp. 1325 - 1331.

[10] S.M. Brahma, “ New fault-location method for a single multi-terminal transmission line using synchronized phasor measurements", IEEE Transactions on Power Delivery, Vol. 21, No. 3, July 2006, pp. $1148-1153$.
[11] Eyada A. J. Alanzi , Prof. Mohd Zaid Abdullah , Dr. Nor Ashidi Mat Isa, "Accurate Fault Location of EHV Teed Feeder using RBFNN". IJCSNS International Journal of Computer Science and Network Security, Vol. 7, No.12, December 2007, pp. 282-286.

[12] Adel A. Elbaset and Takashi Hiyama: "Fault Detection and Classification in Transmission Lines Using ANFIS", IEEJ Trans. IA, Vol. 129, No. 7,2009, pp.705-713.

[13] Anamika Jain, A.S. Thoke, and R. N. Patel, "Classification of single line to ground faults on double circuit transmission line using ANN", International Journal of Computer and Electrical Engineering, Vol.1 No. 2, June 2009, pp.197-203.

[14] Math works Inc USA, "Neural Networks Toolbox".

[15] Martin T. Hagan and Mohammad B. Menhaj, "Training feedforward networks with the marquardt algorithm", IEEE Trans. on Neural Networks, Vol. 5, No. 6, pp. 989993, 1994. 